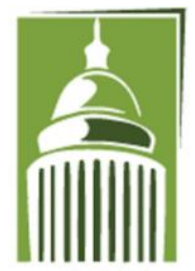

A R F
Global Proceedings Repository

American Research Foundation

ISSN 2476-017X

Available online at http://proceedings.sriweb.org

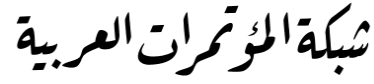

http://arab.kmshare.net/

The 10th International Scientific Conference

Under the Title

"Geophysical, Social, Human and Natural Challenges in a Changing Environment"

$$
\begin{aligned}
& \text { المؤنمر العلمي الدولي العاشر } \\
& \text { تحت عنوان "التحديات الجيوفيزيائية والاجتماعية والانسانية و الطبيعية في بيئة متغيرة" } \\
& 25 \text { - } 26 \text { يوليو - تموز } 2019 \text { - اسطنبول - تركيا } \\
& \text { http://kmshare.net/isac2019/ }
\end{aligned}
$$

\title{
Prevalence of low back pain among Jordanian nurses and its associated factors
}

\author{
Ala' A. Salme
}

\begin{abstract}
Low back pain (LBP) is a public health problem, the nurses of hospitals have a high prevalence of low back pain among healthcare system workers, LBP is work-related health problem, which affects on health of nurses, and on their productivity.

LBP is causes massive pain in some cases, disability, decreased physical performance, increase absenteeism, and other psychosocial effects. This study aimed to explore the factors and predictors associated with LBP among Jordanian nurses in governmental hospitals in Amman. And it will define the prevalence of LBP among them in these hospitals. A descriptive cross-sectional study conducted on a convenience sample of nurses, selected from a governmental hospital in capital of Jordan. A self-administered questionnaire used to collect data by distributing the questionnaire to nurses directly. A descriptive method-using mean, standard deviations and percentages was used, in addition to chi-square tests. The results of this study showed that the point prevalence rate of LBP among Jordanian was $71.8 \%$. The LBP is an occupational health problem for nurses in governmental hospitals in Jordan, There is high percentage of nurses suffer from episodes of LBP daily, and more than $90 \%$ have attacks of LBP at least one time during last year. Lifting patients is one of most serious risk factors, which are cause LBP among nurses in Jordan
\end{abstract}




\section{Global Proceedings Repository \\ American Research Foundation}

ISSN 2476-017X

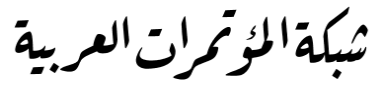

http://arab.kmshare.net/

AR F

Available online at http://proceedings.sriweb.org

Keywords: Jordan; low back pain; nurses; prevalence

\section{Introduction:}

Low back pain (LBP) is considered an important clinical and public health problem (1).

The nurses of hospitals have a high prevalence of low back pain (2).

Several studies confirmed predominant LBP among nurses. A wide spectrum of LBP varied internationally (3). The prevalence of work related LBP in nursing is the highest of any profession internationally (4).

LBP is viewed as an economic problem .It has been estimated that nurses' back injuries cost over 6 million US\$ as compensation and medical payments in the United States. Furthermore, nurses' compensation for back injury comprises $56.4 \%$ of all compensation costs and $55.1 \%$ of all medical costs (15)

\subsection{Study Significance}

This study will focus on factors and predictors associated with LBP among Jordanian nurses in governmental hospitals in Amman. And it will also define the prevalence of LBP among them in these hospitals.

The results of this study will help the decision makers to develop a preventive strategy to protect nurses from serious health problems. This is consequently will promote the quality of services delivered to patient.

\subsection{Study Objectives}

1- To determine the prevalence of low back pain among the Jordanian nurses in governmental hospitals in Amman. 
Global Proceedings Repository

American Research Foundation

ISSN 2476-017X

Available online at http://proceedings.sriweb.org

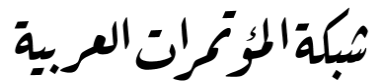

http://arab.kmshare.net/

A R F

2- To determine statistically the predictors of low back pain among Jordanian nurses in governmental hospitals in Amman.

\section{Literature Review:}

\subsection{Low back pain:}

Low back pain is "Pain localized below the costal margin and above the inferior gluteal folds, either with or without referred leg pain" (10).

The causes of the majority of LBP are unknown; current tests cannot identify a pathological cause for the pain in at least $85 \%$ of cases $(12,13)$.

A study was conducted to investigate the possible causes of low back pain and its prevalence. The participants (Nurses, Office workers, Market vendors, Peasants and Urban dwellers) were 204 ones referred with LBP as the principal complaint. The main findings showed that the point prevalence of LBP was $20 \%$, the percentage of $(62.3 \%)$ of the patients had mechanical (simple) LBP with no definable patho-anatomic causative factor (non-specific). While $17.2 \%$ had serious spinal pathology and $1.5 \%$ had no definite cause. The main finding concluded that the non-specific a etiology of low back pain was the most common cause (26).

Mechanical LBP can result from various spinal structures including; ligaments, facet joints, periosteum, the paravertebral musculature and fascia, blood vessels, the annulus fibrosis and spinal nerve roots. However, the exact disorder cause is unidentified .furthermore, Mechanical (non-specific) disorders were the cause in $90 \%$ of cases of LBP, and $10 \%$ were due to the systemic illness (11).

As a negative outcome of the Long Term Low Back Pain, a study was conducted by Von Korff M (1994); it showed that low back pain is quite persistent with strong fluctuations in severity of complaints expressed by recurrent episodes interspersed with periods free from pain (32).

In a study conducted Between (1998 - 2001) to determine the risk factors for short-term (<or=14 days) and long-term (>14 days) sick leave related to LBP among scaffolders, the finding from this study indicated that physical load was a risk factor for sickness absence for less than 2 weeks. The severe LBP was a risk factor for sickness absence both less than and more than 2 weeks (33). 


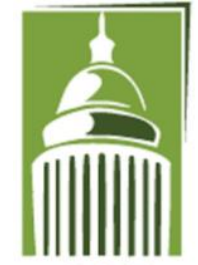

ARF
Global Proceedings Repository

American Research Foundation

ISSN 2476-017X

Available online at http://proceedings.sriweb.org

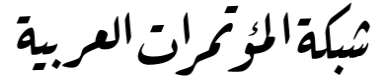

http://arab.kmshare.net/

\subsection{The Prevalence of Low Back Pain among Nurses:}

Nursing has been associated with high prevalence of back disorders $(44,45)$. Nurses have been in the fifth order in occupations claiming worker compensation for low back injuries (46). Nursing personnel are listed as one of the top ten occupations of workrelated musculoskeletal disorders (71)

A study reported that in nursing, as a career, nurses are in an occupational group in which they experience more serious back injuries and occupational low back pain than most other professions (47). It is worth noting that the frequency of back injuries in nurses that may cause disability is among the highest of all worker groups (48).In another study, the Occupational back pain in nurses considered as a major source of morbidity in the health care environment. Moreover, nurses have the highest rate of low back pain with annual prevalence of $(40-50 \%)$ and a lifetime prevalence of $(35-80 \%)$ among health care personnel (58).

The point prevalence was determined in several studies, a cross sectional study conducted in Italy among 132 of hospital nurses, the point prevalence was $40 \%$ (9). And $54.7 \%$ point prevalence rate of LBP reported in Switzerland nurses (6), while the point prevalence rate among Canadian nurses was 30\% (44). In a another study reported that the point prevalence of LBP was $77 \%$ among hospital nurses in a Greek Hospital (51)

Several studies reported varied annual prevalence rates of nursing related low back pain range from $35.9 \%$ in New Zealand, $47 \%$ in the United States, and $66.8 \%$ in the Netherlands (50). In a comparative studies, it was reported that the one year prevalence of LBP in British hospital nurses was 38\%, in Japanese hospital nurses $54.7 \%$, and in Swedish hospitals 56\% (52).In another study conducted on nurses in Hong Kong, the authors found that the annual prevalence of LBP ranged from (43.1\% to $69.7 \%)$, the incidence of acute LBP (2 week duration) was $94 \%$ (48).

The reasons behind the prevalent LBP among nurses are thought to be due to the nature of the nursing job which requires nurses to undertake manual handling tasks (49).

\subsection{The Relationship between LBP and Selected Variables:}




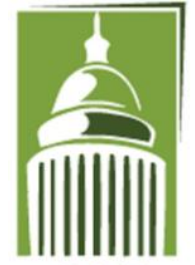

A R F
Global Proceedings Repository

American Research Foundation

ISSN 2476-017X

Available online at http://proceedings.sriweb.org

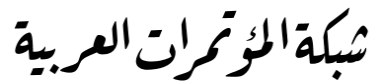

http://arab.kmshare.net/

\subsubsection{Age}

The relationship between age and LBP is still debatable in literature. Several studies showed a positive relationship between age and $\operatorname{LBP}(5,23)$; certain studies indicated bell shaped relationship between age and $\operatorname{LBP}(70,54)$, and another study showed no relationship $(6,67)$

In a study conducted among nurses in South-west Nigeria, the prevalence rate of workrelated musculoskeletal disorders (WMSDs) Increased with increasing age but dropped sharply in those above 50 years old. In addition to that, the rate of WMSDs was not significantly associated with age $(\mathrm{p}=0.329)(70)$.

According to Kirkaldy-Willis and Burton (1992), LBP has a tendency to start in the third decade, and it is more frequent during middle age and tends to be less frequent in the elderly (54).

Manga et al (1993) reported that LBP reaches its peak of incidence between the ages of 25 and 55 (5).

In a cross-sectional study conducted to determine the annual prevalence and risk factors of LBP among nurses in a typical Nigerian Specialist Hospital. The participants were 408 (148 males and 260 females). The authors found that prevalence rate of LBP among nurses increased with age, (age group < 35, 36-45 and > 46), the results were reported as $(6.3 \%)$, $(27 \%)$ and $(66.7 \%)$ respectively $(23)$.

In a study conducted Among 330 Korean Hospital Nurses to determine the epidemiology of musculoskeletal symptoms (MSS), the researchers did not find any relationship between age and MSS (67), and in a longitudinal study performed over 8 years, the results revealed no significant association between the age and low back pain (6).

\subsubsection{Gender}

Several studies in literature showed contradicting findings regarding the relation between LBP and gender among nurses. Some studies reported higher prevalence of LBP among male nurses (53), while other studies showed a slightly higher prevalence of LBP among female nurses than male nurses $(55,56)$. Another study reported that the rate of LBP were higher in women than in men in all ages above 30, (41.7\% Vs 31.2\%, 


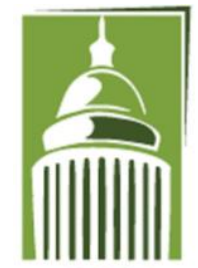

A R F
Global Proceedings Repository

American Research Foundation

ISSN 2476-017X

Available online at http://proceedings.sriweb.org

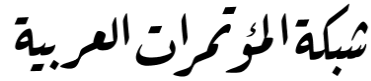

http://arab.kmshare.net/

respectively), but, the prevalence rates in the (18 - 29) year age group was comparable (1). In other studies the increased prevalence of LBP in females has been attributed to childbirth and menstruation $(47,55)$

A more recent cross-sectional study (23) was conducted to determine the relationship between LBP and gender among nurses in a typical Nigerian Specialist Hospital. The participants were 408 (148 males and 260 females). Female nurses had more prevalence of LBP (68\%) than the male nurses (32\%).

\subsubsection{Physical Exercise}

Physical exercise provides a beneficial effect in case it is practiced in 30 cumulative minutes or more on most days of the week (45). The prevalence of LBP can be reduced successfully in case of practicing exercises designed to strengthen the muscles of the back (49). In another study, researchers found that the physical exercise has a positive effect in the prevention of back pain of nurses (69).

On the other hand, a study indicated that there was limited evidence that physical exercises have effects in preventing new episodes and no evidence of effect of exercise to decrease the level of back pain (68)

\subsubsection{Smoking}

There is evidence in literature $(55,59)$ regarding the positive association between smoking and LBP .Several theories were put to explain this association. Smoking reduces vertebral blood flow, which may lead to intervertebral disc degeneration. Smoking has also been associated with anxiety and depression, which are found to exacerbate back pain. Moreover, it has been reported that smoking produces a chronic cough; this gives rise to increased intra-abdominal and intra-discal pressure, leading to increased mechanical stress on the lumbar discs.

\subsubsection{Nursing manual Activities:}

It has been shown that certain occupations work tasks seem to have a higher risk of LBP (19). In nursing, the performance nature of daily work in terms of manual handling and transferring of patients have been found to be associated with LBP (60). 


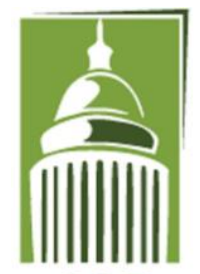

A R F
Global Proceedings Repository

American Research Foundation

ISSN 2476-017X

Available online at http://proceedings.sriweb.org

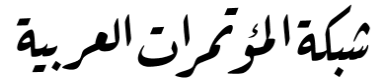

http://arab.kmshare.net/

Direct patient contact activities of transferring and lifting patients are the two most frequent causes of occupational LBP and account for (79\% of LBP) in nurses job(7). In a study has explored the relationship between work factors and LBP, in both nursing personnel and other occupational groups. Lifting, frequent twisting and bending associated with the risk of LBP (22). Repetitive lifting and other frequent activities like moving furniture were associated with LBP (57).

In epidemiological study, it was reported that repetitive lifting, frequent bending and twisting were factors which develop the LBP among nurses, in addition to that, heavy physical workload had a major role in the development of LBP in nurses (73).

A cross-sectional survey conducted in South-west Nigeria to determine the 12-months period of work related musculoskeletal disorders among nurses. The results showed that lifting or transferring patients were the most job risk factors for LBP and other musculoskeletal disorders (70).

The results of another study indicated that repetitious movement, lifting patients, lifting heavy loads, working in awkward postures, and transferring patients out of bed and from the floor are risk for work related musculoskeletal disorders among nurses (72).

In another a study reported in Japan the manual handling, and lifting of patients is 2.6 times to have LBP among nurses (66)

\subsubsection{Qualifications of nurses:}

A list of risk factors that are Associated with LBP among Nurses were highlighted in literature. One of thee risk factors is the qualifications of nurses. Aid nurses were at greater risk for back pain than registered nurses (17). Another study reported that the Aid Nurses doing both emotional and heavy physical work, they are group of the occupational groups that are most frequently affected by LBP (22).

Registered nurses in the seventh rank, nursing aides and orderlies are the highest ranked groups among all occupations for back injuries (24).

\subsubsection{Experience (Working in years):}




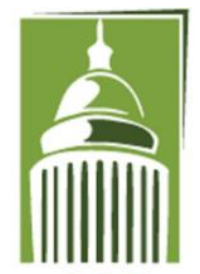

ARF
Global Proceedings Repository

American Research Foundation

ISSN 2476-017X

Available online at http://proceedings.sriweb.org

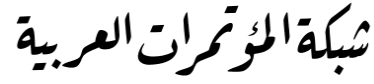

http://arab.kmshare.net/

It was reported that the experience in nursing is a significant risk factor, so that junior nurses (less than 2 years experience) are at greater risk compared with senior nurses (17).

A cross-sectional survey conducted in South-west Nigeria to determine the experience in nursing and work-related musculoskeletal disorders (WMSDs) among nurses. Nurses of more than 20 years of clinical experience are about 4 times more likely to develop workrelated musculoskeletal disorders than those who of (11-20) years of experience in nursing (CI 1.08-13.4), and about 2 times than those of (1-10 )years (CI 0.58-5.53) (70).

\subsubsection{Department (Work place):}

It is considered as one of the risk factors of LBP. A cross-sectional study was conducted to determine the prevalence of LBP among intensive care unit nurses in South Korean hospitals. The study sample consists of 1345 nurses in 65 intensive care units included in 22 South Korean hospitals. Low back pain prevalence was measured by the frequency of back pain (always, once a week, once a month or once in two or more months) during the past year, the nurses who had low back pain at least once a month accounted $90 \cdot 3 \%$. Nurses in other specialties, excluding pediatric intensive care units, had a greater likelihood of low back pain. Specialty medical intensive care unit nurses had the greatest probability of low back pain. Nurses those who had (2-4) years of working experience in intensive care units had the greatest probability of low back pain. Finally, the study concluded that the highest prevalence of low back pain was found in intensive care unit nurses, although they comprise a very young workforce in Korea (62).

In study conducted in rural Japanese hospital among female nurses reported that working in the surgical department was shown to increase the risk of LBP or any MSD 2.7 times when compared to nurses in the other departments (63).

Another cross-sectional study was conducted to determine the relationship between work place and LBP among nurses in a typical Nigerian Specialist Hospital. The participants were 408, obstetric and gynecology reported the highest incidence of LBP (27\%), while tutors and nursing administrators reported the least (4.3\%) each. The highest in obstetric and gynecology department might be related to the fact that only female nurses work in this department and prevalence is more in females. It might also be related to the work pressure in the department mentioned above (23). 


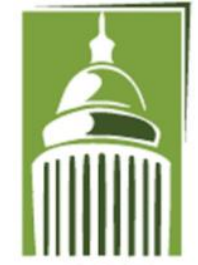

A R F
Global Proceedings Repository

American Research Foundation

ISSN 2476-017X

Available online at http://proceedings.sriweb.org

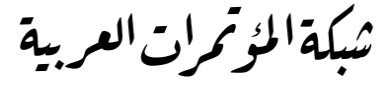

http://arab.kmshare.net/

\subsubsection{Onset of LBP:}

A study was conducted among nurses in South-west Nigeria to determine the period and point prevalence of (WMSDs) among nurses, the results showed that $54.6 \%$ of nurses reported gradual onset of WMSDs, $20.2 \%$ of them reported sudden onset of WMSDs, while $25.2 \%$ reported as unknown onset (70). Another cross sectional study reported that the majority $(80 \%)$ of nurses described their LBP as gradually onset, while $20 \%$ reported sudden onset (57).

\subsubsection{Number of working hours per week:}

In study was conducted among nurses in South-west Nigeria. The number of hours per week in direct patient care was not significantly associated with work related musculoskeletal disorders among nurses $(\mathrm{x} 2=22.905 ; \mathrm{p}=0.262)(70)$.

\subsubsection{Severity of LBP:}

A recent cross-sectional study was conducted to determine the prevalence and risk factors of LBP among 408 nurses in a typical Nigerian Specialist Hospital. (43.3\%) of nurses reported that their level of LBP was mild, and (38.6\%) reported that their level of LBP was moderate, while (18\%) reported that as severe pain (23).

\subsubsection{Day's off-duty due to LBP:}

In a cross-sectional study conducted, about (35.67\%) of nurses reported that LBP had been absent in one time or the other for the past 12 months. Out of this, $(86 \%)$ were females and the male nurses were (14\%). Female nurses reported 164 (81.19\%) days, while males reported 38 (18.81\%) days off-duty (23).

Another cross-sectional study (57) reported that nurses who had taken sick leave from work due to LBP accounted (43.2\%).

In another study indicated that nurses lost $(750,000)$ days annually as a result of LBP $(61)$. 


\section{Global Proceedings Repository \\ American Research Foundation}

ISSN 2476-017X

Available online at http://proceedings.sriweb.org

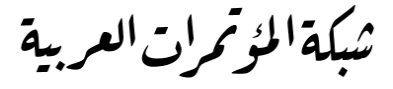

http://arab.kmshare.net/

\section{Material and Methods}

\subsection{Study Design and Setting:}

This is a descriptive cross-sectional study. The population of this study included hospital nursing staff in Amman hospitals in Jordan.

\subsection{Sampling Populations:}

The population of the study is comprised of all nurses working in governmental hospitals in Amman.

The governmental hospitals are (Al-Basher hospital, Prince Hamza hospital and Dr. Jamel Al-Totanje hospital). The nurses include staff nurses, associated nurses, and aid nurses in all units and departments in hospital and at all shifts

\subsection{Inclusion and Exclusion Criteria}

\subsubsection{Inclusion Criteria:}

1. Nurses in full-time employment.

2. Nurses between the ages of 18 and 45 .

3. Nurses more than 2 years experience

\subsubsection{Exclusion Criteria:}

1. Any questionnaire that incomplete.

2. Any nurse had previous low back pain before nursing work.

3. Any nurse had any structural deformities of the spine or cancer. 
Global Proceedings Repository

American Research Foundation

ISSN 2476-017X

Available online at http://proceedings.sriweb.org

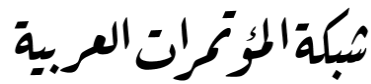

http://arab.kmshare.net/

4. Any nurse had menstruation or pregnant.

\subsection{Study Sample:}

A Convenience sample of 403 nurses was selected for this study. The nurses were selected from Al-Basher hospital accounted 239; the nurses from Prince Hamza hospital were 100 and 64 nurses from Dr.Jamel Al-Totanje hospital.

\subsection{Selection Procedure:}

A letter of The Permission to conduct this research in the selected hospitals (Al-Basher hospital, Prince Hamza hospital and Dr.Jamel Al-Totanje hospital) was obtained from Jordanian Ministry of Health. The letter of The Permission was hand delivered to the administration in each of these hospitals. All nurses on duty at the time of visit to the assigned hospital were invited to participant in the study. Study participants were handed a self administered questionnaires to fill at their convenience and handed it back to the research.

\subsection{Study Instrument}

The pilot study tested of the final version of the modified questionnaire before being used by distributed it to 10 nurses in different positions and work place. The modified questionnaire was well understood. The questionnaire translated to Arabic version and then to English version. The original questionnaire was pre valid by Yip (48); it was used as the tool for this study.

\subsection{Data collection}

The data was collected by using a self administered questionnaire by distributing the questionnaire as mentioned above. Conveniently sample technique was used depend on availability on a particular shift. The nurses received copy of the questionnaire, were given a letter of information, and were given a letter of consent form. The questionnaire was translated to Arabic version and then to English version, it included three parts. The first part gathered information on Socio-demographic characteristics of the participants. Items in this part involved demographic characteristics; e.g. age, sex, and marital status. The 


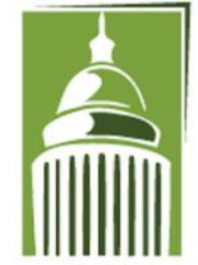

ARF
Global Proceedings Repository

American Research Foundation

ISSN 2476-017X

Available online at http://proceedings.sriweb.org

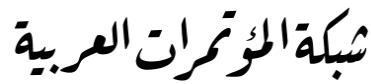

http://arab.kmshare.net/

second part included work position, experience, and the intense and frequency of nursing activity. Third part was the history of low back pain and its characteristics.

\subsection{Data analysis procedure:}

The data was analyzed using the Statistical Package for Social Sciences (SPSS, version 15). Frequencies and percentages were used to describe data. Chi- square and cross tables was used. Odd ratio and $95 \%$ confidence interval were also used. The significance of association was tested at an alpha level of $<0.05$.

\section{Results:}

A total of 403 nurses did participate in this sample study divided into (239 nurses from Al-basher hospital, 100 nurses from Prince Hamza hospital, and 64 ones from Dr. Jamel Al-totanje hospital). Only three participants did not complete the questionnaire with a response rate of $99.3 \%$ ). In addition, five participants were more than 45 years old, three nurses had less than 1 year experience in nursing job, four nurses had L.B.P before the nursing job, and two pregnant nurses were excluded from the study leaving a total of 386 nurses participated in all the study procedures.

\subsection{Sociodemographic Characteristics:}

As shown in table (1), female nurses accounted for $50.5 \%$ of this study. The majority of study sample (48.2\%) was between (26-35 years old), while $37 \%$ of participant were between (18-25). The majority of nurses (63.2\%) had body mass index less than 25, while the Overweight nurses were $25.1 \%$.in this study, the majority of nurses $(52.6 \%)$ were single, while the nurses who married accounted (45.9\%). The nurses who had no children accounted for $37 \%$, while the nurses who had 1-2 children were $35.3 \%$, and who had 3-4 children were $19 \%$.

In term of Physical exercises, the majority of participants $(59.1 \%)$ do not perform physical exercises. The nurses who performed physical exercises of less than or equal 3 hours per week were $31.1 \%$, and the nurses who performed physical exercises more than 3 hours weekly were $9.8 \%$. The majority of participants $(77.5 \%)$ in this study were non smoking.

Table (1): Socio-Demographic characteristics.

\begin{tabular}{|c|c|}
\hline Variable & Number \\
\hline
\end{tabular}




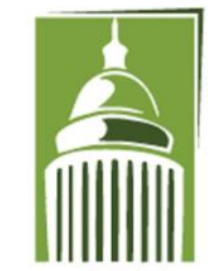

A R F
Global Proceedings Repository

American Research Foundation

ISSN 2476-017X

Available online at http://proceedings.sriweb.org

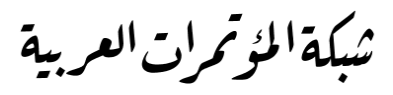

http://arab.kmshare.net/

\begin{tabular}{|c|c|c|}
\hline \multicolumn{3}{|l|}{ Gender } \\
\hline Male & 191 & 49.5 \\
\hline Female & 195 & 50.5 \\
\hline \multicolumn{3}{|l|}{ Age } \\
\hline $18-25$ & 143 & 37 \\
\hline $26-35$ & 186 & 48.2 \\
\hline $36-45$ & 57 & 14.8 \\
\hline \multicolumn{3}{|l|}{ BMI } \\
\hline$<25$ & 244 & 63.2 \\
\hline$(25-<30)$ & 97 & 25.1 \\
\hline$>30$ & 45 & 11.7 \\
\hline \multicolumn{3}{|l|}{ Marital status } \\
\hline Married & 177 & 45.9 \\
\hline Single & 203 & 52.6 \\
\hline Divorce/Widowed & 6 & 1.5 \\
\hline \multicolumn{3}{|l|}{ No. of children } \\
\hline Non & 68 & 37 \\
\hline $1-2$ & 65 & 35.3 \\
\hline $3-4$ & 35 & 19 \\
\hline$>5$ & 16 & 8.7 \\
\hline \multicolumn{3}{|c|}{ Physical exercises (hours / week) } \\
\hline 0 & 228 & 59.1 \\
\hline$\leq 3$ & 120 & 31.1 \\
\hline$>3$ & 38 & 9.8 \\
\hline \multicolumn{3}{|l|}{ Smoking } \\
\hline Yes & 87 & 22.5 \\
\hline No & 299 & 77.5 \\
\hline
\end{tabular}

\subsection{Professional Characteristics:}




\section{Global Proceedings Repository \\ American Research Foundation}

ISSN 2476-017X

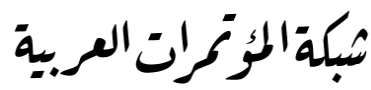

http://arab.kmshare.net/

Available online at http://proceedings.sriweb.org

As shown in table (2), the majority of participants $(65 \%)$ were Registered nurses, while $26.5 \%$ of nurses were Associate nurses. The nurses who work in hospital units accounted $37.6 \%$, while who work in hospital floors were $36 \%$. In this study, the majority of nurses $(83.7 \%$ ) have less than 11 years in nursing experience, and $85.5 \%$ of nurses have a working duty of 60 hours or less than per week.

The majority of nurses in this study $(95.5 \%)$ did not receive training of (low back pain injury prevention training course).

Table (2): professional characteristics.

\begin{tabular}{|c|c|c|}
\hline Variable & Number & Percentage \% \\
\hline \multicolumn{3}{|l|}{ Current post } \\
\hline Registered nurse & 251 & 65 \\
\hline Associate nurse & 102 & 26.5 \\
\hline Aid nurse & 33 & 8.5 \\
\hline \multicolumn{3}{|l|}{ department } \\
\hline Units & 145 & 37.6 \\
\hline Floors & 139 & 36 \\
\hline Light duty dep. & 102 & 26.4 \\
\hline \multicolumn{3}{|l|}{ Experience } \\
\hline \multicolumn{3}{|l|}{$<11$ years } \\
\hline >11years & 64 & 16.3 \\
\hline \multicolumn{3}{|c|}{$\begin{array}{l}\text { Working hours } \text { per } \text { week(in } \\
\text { average) }\end{array}$} \\
\hline$\leq 60$ hours & 330 & 85.5 \\
\hline$>60$ hours & 56 & 14.5 \\
\hline \multicolumn{3}{|l|}{ Training course } \\
\hline Yes & 16 & 4.1 \\
\hline No & 370 & 95.9 \\
\hline
\end{tabular}

\subsubsection{Characteristics of frequency of nursing work activities:}

As shown in table (3), " more frequent" activities were observed among $7.3 \%$ of participants in Assist patient to/from toilet, an $18.7 \%$ in Transfer patient between chair and bed, a $43.5 \%$ in bed Making, 13.5\% in transfer patient to trolley, a $7 \%$ in transfer of patient in/out of bathtub, a $18.4 \%$ in assist patient in walking, a 37.8\% in Move furniture, 


\section{Global Proceedings Repository \\ American Research Foundation}

ISSN 2476-017X

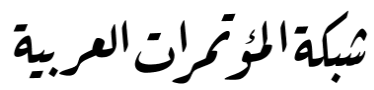

http://arab.kmshare.net/

Available online at http://proceedings.sriweb.org

a $33.9 \%$ in move bed, a $29 \%$ in lifting patients, a $68.1 \%$ in bending or twisting at the waist.

Table (3): Characteristics of frequency of nursing work activities.

\begin{tabular}{|c|c|c|}
\hline Variable & $\begin{array}{l}\text { Number } \\
(\mathrm{n}=386)\end{array}$ & Percentage \% \\
\hline \multicolumn{3}{|c|}{ Assist patient to/from toilet } \\
\hline Less frequent & 358 & 92.7 \\
\hline More frequent & 28 & 7.3 \\
\hline \multicolumn{3}{|c|}{$\begin{array}{l}\text { Transfer patient between } \\
\text { chair/wheel chair and bed }\end{array}$} \\
\hline $\begin{array}{l}\text { Less frequent } \\
\end{array}$ & 314 & 81.3 \\
\hline More frequent & 72 & 18.7 \\
\hline \multicolumn{3}{|l|}{ bed Making } \\
\hline Less frequent & 218 & 56.5 \\
\hline More frequent & 168 & 43.5 \\
\hline \multicolumn{3}{|c|}{$\begin{array}{l}\text { Transfer patient to trolley (e.g. } \\
\text { X-ray) }\end{array}$} \\
\hline Less frequent & 334 & 86.5 \\
\hline More frequent & 52 & 13.5 \\
\hline \multicolumn{3}{|c|}{$\begin{array}{lll}\text { transfer of patient in/out of } \\
\text { bathtub }\end{array}$} \\
\hline Less frequent & 359 & 93 \\
\hline More frequent & 27 & 7 \\
\hline \multicolumn{3}{|l|}{ Assist patient in walking } \\
\hline Less frequent & 315 & 81.6 \\
\hline More frequent & 71 & 18.4 \\
\hline \multicolumn{3}{|c|}{$\begin{array}{l}\text { Move furniture/instrument (e.g. } \\
\text { ECG monitor) }\end{array}$} \\
\hline Less frequent & 240 & 62.2 \\
\hline More frequent & 146 & 37.8 \\
\hline \multicolumn{3}{|l|}{ Move bed } \\
\hline Less frequent & 255 & 66.1 \\
\hline More frequent & 131 & 33.9 \\
\hline
\end{tabular}




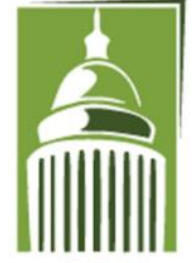

AR F
Global Proceedings Repository

American Research Foundation

ISSN 2476-017X

Available online at http://proceedings.sriweb.org

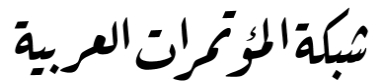

http://arab.kmshare.net/

\begin{tabular}{||c||l||l||}
\hline Carrying or lifting patients & & \\
\hline Less frequent & 274 & 71 \\
\hline More frequent & 112 & 29 \\
\hline Bending/twisting at the waist & & \\
\hline Less frequent & 123 & 31.9 \\
\hline More frequent & 263 & 68.1 \\
\hline
\end{tabular}

\subsubsection{Characteristics of intensity of LBP according to nursing work activities:}

As shown in table (4), "severe intense pain" was observed among 9\% of participants in Assist patient to/from toilet, a $16.9 \%$ in Transfer patient between chair and bed, a $40.8 \%$ in bed making, a 20\% in transfer patient to trolley, a $27.8 \%$ in transfer of patient in/out of bathtub, a 5.9\% in assist patient in walking, a $13.9 \%$ in Move furniture, a $16.8 \%$ in move bed, a $61.7 \%$ in lifting patients, a $48.6 \%$ in bending or twisting at the waist.

Table (4): Characteristics of intensity of LBP according to nursing work activities:

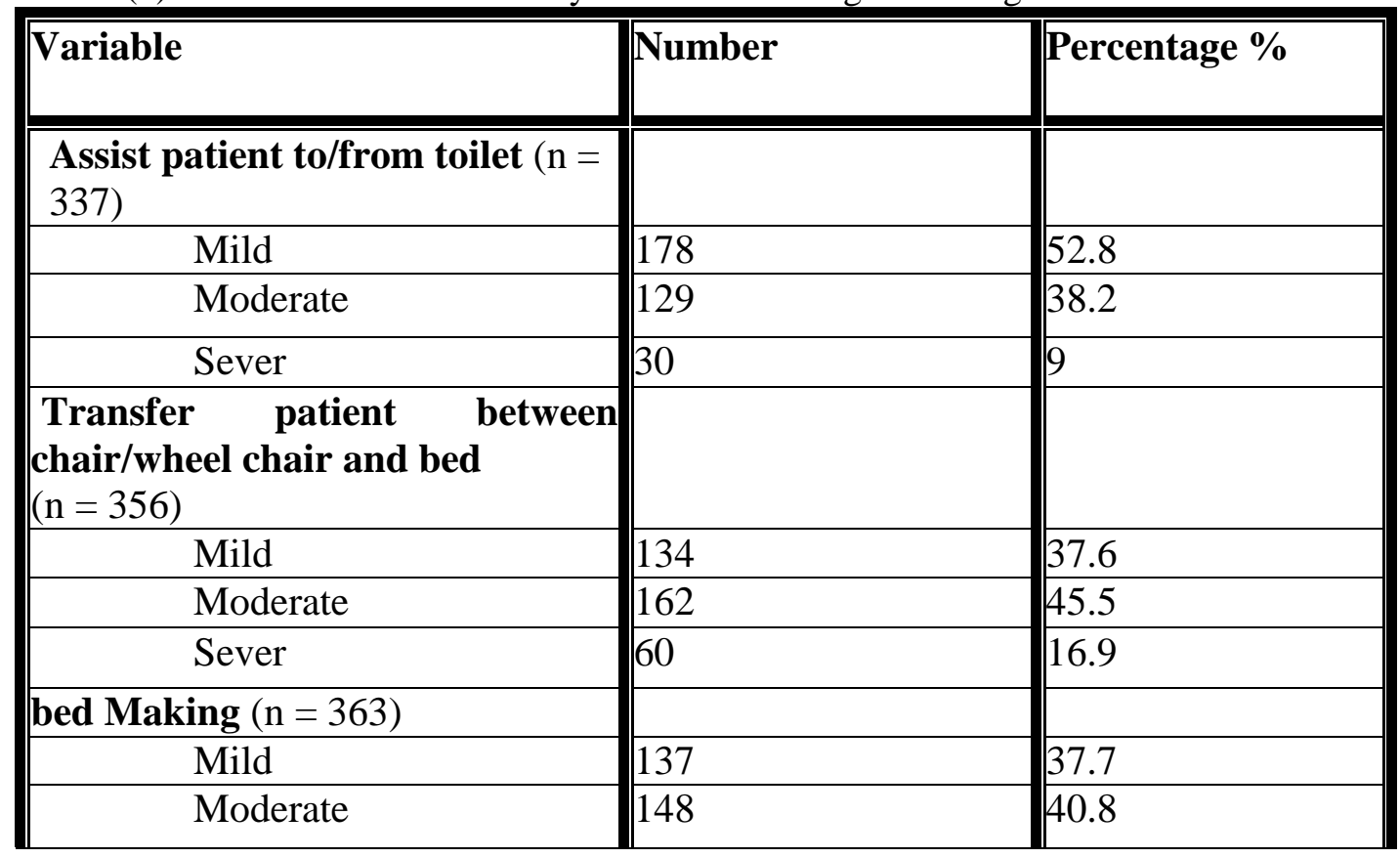




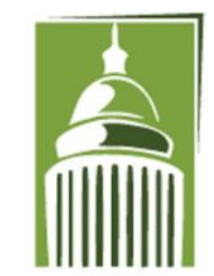

AR F
Global Proceedings Repository

American Research Foundation

ISSN 2476-017X

Available online at http://proceedings.sriweb.org

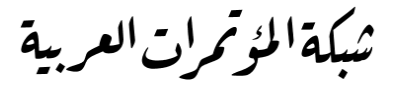

http://arab.kmshare.net/

\begin{tabular}{|c|c|c|}
\hline Sever & 78 & 21.5 \\
\hline \multicolumn{3}{|l|}{\begin{tabular}{|l|} 
Transfer patient to trolley (e.g. \\
X-ray $(\mathrm{n}=355)$
\end{tabular}} \\
\hline Mild & 136 & 38.3 \\
\hline Moderate & 148 & 41.7 \\
\hline Sever & 71 & 20 \\
\hline \multicolumn{3}{|l|}{$\begin{array}{l}\text { transfer of patient in/out of } \\
\text { bathtub }(n=327)\end{array}$} \\
\hline Mild & 129 & 39.4 \\
\hline Moderate & 107 & 32.7 \\
\hline Sever & 91 & 27.8 \\
\hline \multicolumn{3}{|l|}{$\begin{array}{l}\text { Assist patient in walking } \\
(\mathrm{n}=339)\end{array}$} \\
\hline Mild & 197 & 58.1 \\
\hline Moderate & 122 & 36 \\
\hline Sever & 20 & 5.9 \\
\hline \multicolumn{3}{|l|}{$\begin{array}{l}\text { Move furniture/instrument (e.g. } \\
\text { ECG monitor) }(\mathrm{n}=366)\end{array}$} \\
\hline Mild & 169 & 46.2 \\
\hline Moderate & 146 & 39.9 \\
\hline Sever & 51 & 13.9 \\
\hline \multicolumn{3}{|l|}{ Move bed $(n=368)$} \\
\hline Mild & 156 & 42.4 \\
\hline Moderate & 155 & 40.8 \\
\hline Sever & 62 & 16.8 \\
\hline \multicolumn{3}{|l|}{$\begin{array}{l}\text { Carrying or lifting patients } \\
(\mathrm{n}=379)\end{array}$} \\
\hline Mild & 29 & 7.7 \\
\hline Moderate & 116 & 30.6 \\
\hline Sever & 234 & 61.7 \\
\hline \multicolumn{3}{|l|}{$\begin{array}{l}\text { Bending/twisting at the waist } \\
(\mathrm{n}=381)\end{array}$} \\
\hline Mild & 47 & 12.3 \\
\hline
\end{tabular}




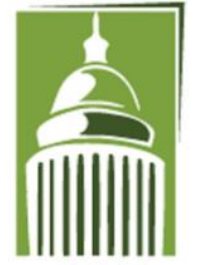

A R F
Global Proceedings Repository

American Research Foundation

ISSN 2476-017X

Available online at http://proceedings.sriweb.org

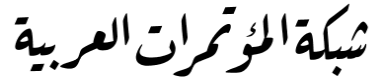

http://arab.kmshare.net/

\begin{tabular}{|l||l||l||}
\hline Moderate & 149 & 39.1 \\
\hline Sever & 185 & 48.6 \\
\hline
\end{tabular}

\subsection{Prevalence of LBP among Nurses:}

In this study, the point prevalence of L.B.P among study subjects was $71.8 \%$.

\subsection{Characteristics of nurses with LBP:}

As shown in table (5), $83 \%$ of nurses reported that their LBP began gradual. The percentage of nurses who appeared in pain daily during a last year was (30.6\%), those who had (1-6) episodes last year was (32\%), and (28\%) of nurses had more than 6 episodes last year.

The majority of nurses $(65.5 \%)$ described their LBP as moderate pain, while (23.4\%) classified their LBP themselves as severe. The mean duration of the episodes of LBP was 3.3 hours (range 1 hour -12 hours). The majority of nurses (80.5\%) reported the need for bed rest due to their LBP. The nurses who had no sick leaves during last year were (50.5\%), and those with less than or equal 5 days sick leaves during last year due to LBP accounted (41.9\%) of nurses. In this sample, the nurses who perceived lifting patients is the cause of their LBP were (85\%), those who perceived "long Standing" is the cause were (83\%), and (83\%) perceived Bending is the cause of their LBP.

Table (5): Characteristics of LBP.

\begin{tabular}{|c|c|c|}
\hline Variable & Number & Percentage \% \\
\hline \multicolumn{3}{|l|}{ Onset } \\
\hline Gradually & 230 & 83 \\
\hline Suddenly & 47 & 17 \\
\hline \multicolumn{3}{|l|}{ No. of episodes } \\
\hline 0 & 26 & 9.4 \\
\hline Daily & 85 & 30.6 \\
\hline $1-6$ & 89 & 32 \\
\hline$>6$ & 77 & 28 \\
\hline \multicolumn{3}{|l|}{ Intensity } \\
\hline Mild & 31 & 11.1 \\
\hline Moderate & 182 & 65.5 \\
\hline
\end{tabular}




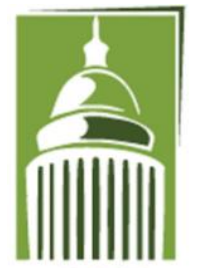

AR F
Global Proceedings Repository

American Research Foundation

ISSN 2476-017X

Available online at http://proceedings.sriweb.org

\begin{tabular}{|c|c|c|}
\hline Sever & 65 & 23.4 \\
\hline \multicolumn{3}{|l|}{ Bed rest } \\
\hline Yes & 223 & 80.5 \\
\hline No & 54 & 19.5 \\
\hline \multicolumn{3}{|l|}{ No. of sick leave } \\
\hline None & 140 & 50.5 \\
\hline$\leq 5$ Days & 116 & 41.9 \\
\hline$>5$ Days & 21 & 7.6 \\
\hline \multicolumn{3}{|c|}{$\begin{array}{l}\text { Nurses' Perception of Causes of } \\
\text { LBP }\end{array}$} \\
\hline Lifting patients & 236 & 85 \\
\hline Long Standing & 230 & 83 \\
\hline Bending & 203 & 83 \\
\hline Twisting & 205 & 74 \\
\hline
\end{tabular}

\subsection{The factors which associated with LBP:}

The factors significantly associated with low back pain in this sample were included in a Binary logistic regression model to assess the net effects of each of these variables on LBP after controlling for the effect of other variables in model. The finding from logistic regression analysis indicated that the risk of having LBP among females was 1.9 times higher than males ( $\mathrm{p}$-value $=0.007$ ). Among those who do not perform exercise the risk of having LBP is 3.1 times compared with who perform physical exercise for more than 3 hours weekly 


\section{Global Proceedings Repository \\ American Research Foundation}

ISSN 2476-017X

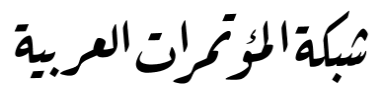

http://arab.kmshare.net/

Available online at http://proceedings.sriweb.org

(p-value $=0.002$ ), and the risk of having LBP is 2.2 times for those who do perform physical exercise for less than or equal 3 hours weekly compared with those who perform physical exercise for more than 3 hours weekly ( $\mathrm{p}$-value $=0.036)$, table $(9)$.

Table (9): The factors which associated with LBP.

\begin{tabular}{||l||l|l||}
\hline Variable & OR & P value \\
\hline \hline Sex & & 0.007 \\
\hline Males & 0.532 & \\
\hline Females & 1 & \\
\hline Physical exercise & & 0.007 \\
\hline 0 & 0.32 & 0.002 \\
\hline$\leq 3$ & & \\
\hline$>3$ & 0.446 & 0.036 \\
\hline
\end{tabular}

\section{Discussion:}

This study conducted to determine the prevalence of Low back pain (LBP) among Jordanian nurses in governmental hospitals in Amman, and to determine statistically the predictors of low back pain among them.

The point prevalence rate of LBP was $71.8 \%$. This figure is lower than the $77 \%$ point prevalence rate reported in Greek nurses (51), but it is higher than the point prevalence rate 


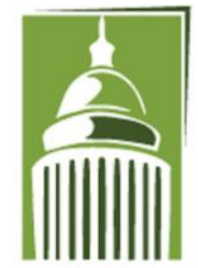

A R F
Global Proceedings Repository

American Research Foundation

ISSN 2476-017X

Available online at http://proceedings.sriweb.org

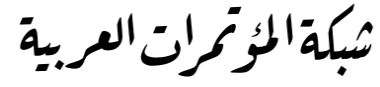

http://arab.kmshare.net/

of LBP $54.7 \%$ reported in Switzerland nurses (6), the point prevalence rate among Canadian nurses $30 \%$ (44), and the $40 \%$ point prevalence rate among Italian nurses (9).

On other hand, the prevalence rate of LBP reported in this study is relatively high compared to the annual or life time prevalence reported among nurses in New Zealand (35.9\%), in United States (47\%), and in the Netherlands (66.8\%) (50). However, our data is comparable to the $72 \%$ rate reported among Japanese nurses and the $70 \%$ rate among Korean nurses, but lower than the $78 \%$ prevalence rate reported among Taiwanese nurses (3).

It is clear that LBP among nurses in Jordan is higher than in any western such as (USA, Canada, and Italy).

\subsection{Conclusion:}

1- LBP is an occupational health problem for nurses in governmental hospitals in Jordan.

2- There is high percentage of nurses suffer from episodes of LBP daily, and more than $90 \%$ have attacks of LBP at least one time during last year.

3- Lifting patients is one of most serious risk factors which are cause LBP among nurses.

4-The majority ( $85 \%$ ) of this study was young nurses, and the prevalence rate was high, so we have to be aware of this problem which is negatively affect the quality of patients care delivered.

5- The LBP is among the causes for days lost among nurses.

6- Lifting patients, moving beds and furniture, not performing physical exercise, female gender are the associated factors in this study.

\subsection{Recommendations:}




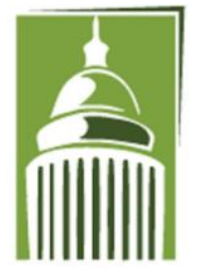

A R F
Global Proceedings Repository

American Research Foundation

ISSN 2476-017X

Available online at http://proceedings.sriweb.org

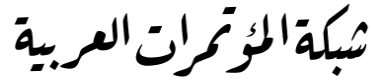

http://arab.kmshare.net/

1- Put optimal strategies and Ergonomics that focus on manual handling tasks and lifting patients, by using lifting assistance devices like (cranes and hoists).

2- Further research on the association between psychosocial factors and LBP among nurses is needed, such as (job satisfaction, work organization, occupational stress, high demands, job insecurity, and lack of social support).

3- Increase attention for these nursing problems such as nursing shortage, overloads tasks, improper ratio between nurses and patients.

4- Provide training courses and Health education programs for nurses to prevent and protect themselves from this problem.

5- Nurses have to take enough rest times during the work shift and decrease daily shift hours.

6- It is recommended to nurses to do regular exercises to prevent low back injuries and pain as protective strategy.

\section{References:}

1- Papageorgiou, A.C. Croft, P.R. Ferry, S. Jayson, M. Silman, A, J. 1995. Estimating the Prevalence of Low Back Pain in the General Population. Spine. 20, (17) 1889-1894.

2- Smedley, J. Inskip, H. Trevelyan, F. Buckle, P. Cooper, C. Coogan, D. 2003. Risk Factors for Incident Neck and Shoulder Pain in Hospital Nurses. Occupa Environ Med. 60, 864-869

3- Lee, Joon Hee, Hoshino, Yuichi, Kariya, Yusei, Chen, Ching-Lang, epidemiological comparison of LBP in three Asian countries, Journal of orthopaedic surgery 1998;33(12),1224.

4- Nelson, A. Fragala, G. and Menzel, N. 2003. Myths and facts about back injuries in nursing. American Journal of Nursing. 103 (2) 32-40.

5- Manga, P. Angus, D.E. and Swan, W.S. 1993. Effective Management of Low Back Pain: It's Time to Accept the Evidence. Journal of the Canadian Chiropractic Association. 37 (4), 221-229.

6- Maul, T Läubli, A Klipstein, H Krueger , course of LBP among nurses: A longitudinal, occup Environ Med 2003;60:497-503. 


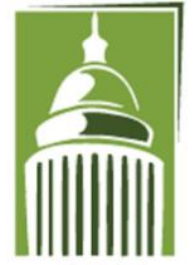

A R F
Global Proceedings Repository

American Research Foundation

ISSN 2476-017X

Available online at http://proceedings.sriweb.org

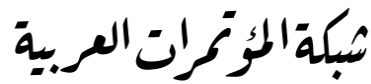

http://arab.kmshare.net/

7- French, P. Lee, F. Liu, S. Luk, K.B. Wong, H. 1997. The Prevalence and Cause of Occupational Back Pain In Hong Kong Registered Nurses. Journal of Advanced Nursing Studies. 26, 380-388.

8- Mayer TG, Gatchel RJ, Mayer H, Kishino ND, Keeley J, Mooney Y. A prospective twoyear study of functional restoration in industrial low back injury. An objective assessment procedure. JAMA. 1987;258:1763-1767.

9- Giannandr. F, Mar. P, Bernardini, P. (2004). Assessing the risk of low back pain among healthcare workers using the Obwestry Disability Index (ODI). G Ital Med Lav Erg 26 (Suppl), 246-8 (in Italian).

10) Waddell, G.1987 Volvo award in clinical sciences. A new clinical model for the treatment of low-back pain. Spine, 12(7): 632-44

11) Diamond, S. Borenstein, D. 2006. Chronic Low Back Pain in a Working-age Adult. Best Practice and Research Clinical Rheumatology. 20 (4), 707-720

12- Deyo RA, Weinstein JN. Low back pain. N Engl J Med 2001; 344:363-370.

13- Papageorgiou, A. Ferry S, Et Al. psychologic distress and LBP. Evidence from A Prospective study in the general population. Spine 1995; 20:2731-2737.

14- Hofmann F, Stossel U, Michaelis M, et al. Low back pain and lumbago-sciatica in nurses and a reference group of clerks: results of a comparative prevalence study in Germany. Int Arch Occup Environ Health 2002; 75:484-90.

15- Cohen-Mansfield J, Culpepper WJ, Carter P. Nursing staff back injuries: prevalence and costs in long term care facilities. AAOHN J 1996;44:9-17.

16- Heliovaara M. Occupation and risk of herniated lumbar intervertebral disc or sciatica leading to hospitalization. J Chronic Dis 1987; 40:259-64.

17- Sherehiy B, Karwowski W, Marek T. Relationship between risk factors and musculoskeletal disorders in the nursing profession: a systematic review. Occupational Ergonomics 2004; 4:241-79.

18- Ready AE, Boreskie SL, Law SA, et al. Fitness and lifestyle parameters fail to predict back injuries in nurses. Can J Appl Physiol 1993; 18:80-90.

19- Feyer A, Herbison P, Williamson AM, et al. The role of physical and psychological factors in occupational low back pain: a prospective cohort study. Occup Environ Med 2000; 57:11620.

20- Mostardi R, Noe D, Kovacik M, et al. Isokinetic lifting strength and occupational injury. A prospective study. Spine 1992; 17:189-93.

21- Adams M, Mannion A, Dolan P. Personal risk factors for first-time low back pain. Spine 1999; 24:2497-505.

22- Eriksen, W. D Bruusgaard, S Knardahl. Work factors as predictors of intense or disabling low back pain; a prospective study of nurses' aides. Occup Environ Med 2004; 61:398-404. 


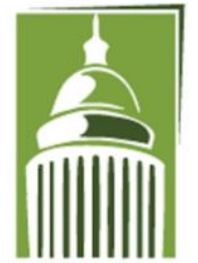

A R F
Global Proceedings Repository

American Research Foundation

ISSN 2476-017X

Available online at http://proceedings.sriweb.org

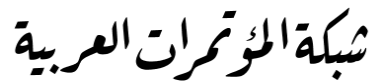

http://arab.kmshare.net/

23- Sikiru L, Hanifa. Prevalence and risk factors of low back pain among nurses in a typical Nigerian hospital. African Health Sciences 2010; 10(1): 26 - 30.

24- Bureau of Labor Statistics. Case and demographic characteristics for work related injuries and illnesses involving days away from work. United States Department of Labor. (2007).

25- WorkCover Corporation of South Australia. Nurses' back injury claims 1999-2002. Adelaide, South Australia: WorkCover Corporation of South Australia, 2004.

26- Galukande. M, Muwazi.S, and Didace B. Mugisa. Aetiology of low back pain in Mulago Hospital, Uganda. African Health Sciences 2005; 5(2) 164-167.

27- Hartvigsen, J. Lauritzen, S. Lings, S. Lauritzen, T. Intensive education combined with low tech ergonomic intervention does not prevent low back pain in nurses. Occup Environ Med 2005; 62:13-17.

28- Yassi A, Tate R, Cooper JE, Snow C, Vallentyne S, Khokhar JB. Early intervention for back-injured nurses at a large Canadian tertiary care hospital: an evaluation of the effectiveness and cost benefits of a two-year pilot project. Occup Med 1995; 45: 209-14.

29- Cooper JE, Tate RB, Yassi A, Khokhar J. Effect of an early intervention program on the relationship between subjective pain and disability measures in nurses with low back injury. Spine, 1996; 21: 2329-36.

30- A Burdorf, J P Jansen. Predicting the long term course of low back pain and its consequences for sickness absence and associated work disability. Occup Environ Med 2006; 63:522-529.

31- Elders LAM, Burdorf A. Prevalence, incidence, and recurrence of low back pain in scaffolders during a three year follow-up study. Spine

2004; 29:e101-6.

32- Von Korff M. Studying the natural course of back pain. Spine

1994; 19:2041-2046S.

33- Elders LAM, Heinrich J, Burdorf A. Risk factors for sickness absence due to low back pain among scaffolders: a 3-year follow-up study. Spine

2003; 28:1340-6.

34- Hoogendoorn WE, Bongers PM, de Vet HC, et al. High physical work load and low job satisfaction increase the risk of sickness absence due to low back pain: results of a prospective cohort study. Occup Environ Med

2002; 59:323-8.

35- Wickstrom GJ, Penti J. Occupational factors affecting sick leave attributed to low-back pain. Scand J Work Environ Health 1998; 24:145-52.

36- Infante-Rivard C, Lortie M. Prognostic factors for return to work after a first compensated episode of back pain. Occup Environ Med 1996; 53:48 8-94. 


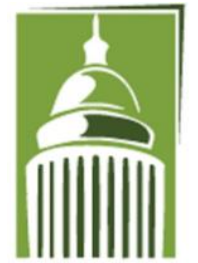

A R F
Global Proceedings Repository

American Research Foundation

ISSN 2476-017X

Available online at http://proceedings.sriweb.org

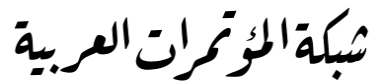

http://arab.kmshare.net/

37- Gatchel RJ, Polatin PB, Mayer TG. The dominant role of psychosocial risk factors in the development of chronic low back pain disability. Spine

1995; 20:2702-9.

38- Sonnenberg FA, Beck R. Markov models in medical decision making: a practical guide. Med Decis Making 1993;13:322-38.

39- Cole DC, Manno M, Beaton D, Swift M. Transitions in self-reported

musculoskeletal pain and interference with activities among newspaper

workers. J Occup Rehabil 2002; 12:163-74.

40- Peter Schenk, Thomas Laeubli, Andreas Klipstein. Validity of pressure pain thresholds in female workers with and without recurrent low back pain. Eur Spine J,2007; 16:267-275.

41- Clauw DJ, Williams D, Lauerman W, Dahlman M, Aslami A, Nachemson AL, Kobrine AI, Wiesel SW (1999) Pain sensitivity as a correlate of clinical status in individuals with chronic low back pain. Spine 24(19):2035-2041.

42- Reeves JL, Jaeger B, Graff-Radford SB (1986) Reliability of the pressure algometer as a measure of myofascial trigger point sensitivity. Pain 24(3):313-321.

43- Maquet D, Croisier JL, Demoulin C, Crielaard JM (2004) Pressure pain thresholds of tender point sites in patients with fibromyalgia and in healthy controls. Eur J Pain 8(2):111117.

44- Smedley, J. Egger, P. Cooper, C. Coggon, D. 1995. Manual Handling Activities and Risk of Low Back Pain in Nurses. Occup Environ Med. 52, 160-163.

45- Yip, Y.B. 2003. New Low Back Pain in Nurses: Work Activities, Work Stress and Sedentary Lifestyle. Journal of Advanced Nursing. 46 (4), 430-440.

46- Owen, B.D., and Garg, A. 1994. Reducing Back Stress Through an Ergonomic Approach: Weighing a Patient. International Journal of Nursing Studies. 31 (6) 511-519.

47- French, P. Lee, F. Liu, S. Luk, K.B. Wong, H. 1997. The Prevalence and Cause of Occupational Back Pain In Hong Kong Registered Nurses. Journal of Advanced Nursing Studies. 26, 380-388.

48- Yip, Y.B. 2001. A Study of Work Stress, Patient Handling Activities and the Risk of Low Back Pain Among Nurses in Hong Kong. Journal of Advanced Nursing. 36 (6), 794-804.

49- Lumm, J.A and Waldron, H.A. 1989. Concerning the Careers: Occupational Health for Health Care Workers. Pp110-111. Great Britain: Reed International Books.

50- Nelson, A. Fragala, G. and Menzel, N. 2003. Myths and facts about back injuries in nursing. American Journal of Nursing. 103 (2) 32-40.

51- Vasiliadou, A. Karvountzis, G.G. Soumilas, A. Roumeliotis, D. Theodosopoulou, E. 1995. Occupational Low-Back Pain in Nursing Staff in a Greek Hospital. Journal of Advanced Nursing. 21, 125-130. 


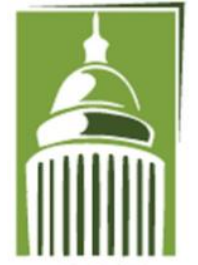

A R F
Global Proceedings Repository

American Research Foundation

ISSN 2476-017X

Available online at http://proceedings.sriweb.org

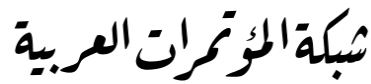

http://arab.kmshare.net/

52- Smith, D, Sato, M. Miyajima, T. Mizutani, T. Yamagata, Z. 2003. Musculoskeletal Disorders Self-Reported by Female Nursing Students in Central Japan: A Complete CrossSectional Survey. International Journal of Nursing Studies. 40, 725-729.

53- Thomas, S. 2005. Zygapophysial Joints and Low Back Pain. Available from. http://www.spineuniverse.com/displayarticle.php/article1898.html. Accessed November 2005. 54- Kirkaldy-Willis, W. H. and Burton, C, V. 1992. Managing Low Back Pain. 3rd edition. USA. Churchill Livingstone. pp. 4-123. ISBN 0-443-08789-x.

55- Toroptsova, N. Benevolenskaya, L. Karyakin, A. Sergeev, I. Erdesz, S. 1995. "Cross Sectional" Study of Low Back Pain among Workers at an Industrial Enterprise in Russia. Spine. 20 (3), 328-332.

56- Skovron, M. Szpalski, M. Nordin, M. Melot, C. Cukier, D. 1994. Sociocultural Factors and Back Pain. A Population-Based Study in Belgian Adults. Spine. 19, (2), 129-137.

57- Dasappa, R.2007.An investigation into factors associated with the development of lower back pain in nurses in the Durban metropolitan area, with particular reference to manual work. Available at http://ir.dut.ac.za/handle/10321/429.

58- Richard F. Edlich, MD, PhD, Kathryne L. Winters,Mary Anne Hudson, RN, BSN, L.D. Britt, MD, MPH,\& William B. Long, MD. (Prevention of Disabling Back Injuries in Nurses by the Use of Mechanical Patient Lift Systems). Journal of Long-Term Effects of Medical Implants, 14(6)521-533 (2004)

59- Boshuizen, H. Verbeek, J. Weel, A. 1992. Do Smokers Get More Back Pain? Spine. 18. $35-40$.

60- Ando, S. Ono, Y. Shimaoka, M. Hiruta, S. Hattori, Y. Hori, F and Yasuhira, T. 2000. Associations of Self Estimated Workloads with Musculoskeletal Symptoms Among Hospital Nurses. Occup Environ Med. 57 (3), 211-216.

61- Triolo PK. Occupational health hazard of hospital staff nurses. Part II Physical, chemical and biological stressors. AAOHN — J. 1988; 37(7):274-279. [PubMed]

62- June.K, Cho.S, Low back pain and work-related factors among nurses in intensive care units. Journal of Clinical Nursing.2011.Volume 20, pages 479-487

63- Smith,D. Ohmura ,K . Yamagata,Z.Minai ,J. Musculoskeletal disorders among female nurses in a rural Japanese hospital. Nursing \& Health Sciences. Volume 5. Pages 185-188, September 2003

64- Roupa, Z. A, Vassilopoulos.THE PROBLEM OF LOWER BACK PAIN IN NURSING STAFF AND ITS EFFECT ON HUMAN ACTIVITY. HEALTH SCIENCE JOURNAL. VOLUME 2, ISSUE 4 (2008).

65- Leighton DJ, Reilly T. Epidemiological aspects of back pain: the incidence and prevalence of back pain in nurses compared to the general population. Occup Med (Lond) 1995;45:263267. 


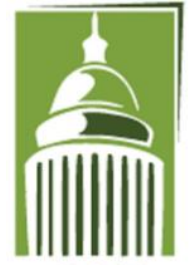

A R F

\section{Global Proceedings Repository}

American Research Foundation

ISSN 2476-017X

Available online at http://proceedings.sriweb.org

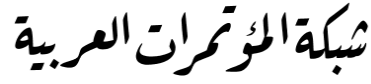

http://arab.kmshare.net/

66- Smith,D. Mihashi,M. Adachi,Y. A detailed analysis of musculoskeletal disorder risk factors among Japanese nurses. Journal of Safety Research 37 (2006) 195 - 200.

67- Smith,D. Choe, M. Jeon. Epidemiology of Musculoskeletal Symptoms Among Korean Hospital Nurses. International Journal of Occupational Safety and Ergonomics (JOSE) 2005, Vol. 11, No. 4, 431-440.

68- Tveito TH, Hysing M \& Eriksen HR. Low back pain interventions at the workplace: a systematic literature review. Occup Med 2004; 54: 3-13. How to prevent low back pain 553.

69- US Preventive Services Task Force. Primary Care Interventions to Prevent Low Back Pain in Adults: Recommendation Statement. Rockville, MD: Agency for Healthcare Research and Quality, 2004. Online Available at: www.ahrq.gov/clinic/3rduspstf/lowback/lowbackrs.htm 70- Tinubu1.B, Mbada.C, Oyeyemi.A, Fabunmi.A. Work-Related Musculoskeletal Disorders among Nurses in Ibadan, South-west Nigeria

a cross-sectional survey. BMC Musculoskeletal Disorders.2010. Vol. 11. Issue 1

71- Bureau of Labor Statistics.( 2002,December 19).survey of occupational inquirers and illness,2001 .U.S. department of labor.

72- Silverstein BA, Fine LJ, Armstrong TJ: Occupational factors and carpal tunnel syndrome. Am J Ind Med 1987, 11:343-358

73- Smedley, J. Egger, P. Cooper, C. Coggon, D. 1997. Prospective Cohort Study of Predictors of Incident of Low Back Pain in Nurses. British Medical Journal. 314, 1225-1228.

74- Punnett L., Fine L.J., Keyserling W.M., Herrin G.D. \& Chaffin D.B.(1991) Back disorders and nonneutral trunk postures of automobile assembly workers. Scandinavian Journal of Work, Environment \& Health 17(5), 337-346. 